\title{
Contribuições do narcisismo para a modificação da teoria do masoquismo
}

\author{
Narcissism contributions to the modification of the masochism \\ theory
}

\author{
Eloy Sampaio ${ }^{1}$; Eva Maria Migliavacca²
}

\section{Resumo}

O narcisismo é um dos conceitos mais importantes da teoria freudiana. Desde o seu surgimento, em 1910, esse fator esteve presente nos escritos do autor e impactou consideravelmente a psicanálise, contribuindo para a passagem da primeira para a segunda tópica, assim como o estabelecimento da segunda teoria pulsional. Ao analisarmos o desenvolvimento histórico do narcisismo, é possível observar que ele teve um período de franco desenvolvimento até 1923. No entanto, após a chamada "virada dos anos 20", ele progressivamente deixou de comparecer nos escritos, ainda que seja possível localizarmos algumas menções nas últimas obras de Freud. É justamente esse cenário que o presente artigo objetiva discutir, ou seja, tentar entender quais são os destinos conferidos ao narcisismo após 1920. Propõe-se que um de seus desdobramentos é a sua contribuição para a modificação da teoria do masoquismo. Assim, o narcisismo continuaria presente na obra de Freud através das suas ressonâncias na abordagem de outros fenômenos.

Palavras-chaves: Narcisismo. Pulsão. Masoquismo.

\begin{abstract}
Narcissism is one of the most important concepts in the freudian theory. Since its appearing, in 1910, it has been present in the author's writings and has impacted psychoanalysis considerably, contributing to the transition from the first to the second topic, as well as to the establishment of the second drive theory. By analyzing the historical development of narcissism, it is possible to observe that it had a period of straightforward growth until 1923. However, after the so called "turn of the twenties", he gradually diminished his writings, even thought it is possible to find some mentions in Freud's last works. It is specifically that scenery the present article intends to discuss, namely to try to understand what are the destinations bestowed to narcissism after 1920. It is suggested that one of its unfoldings is its contribution to the modification of the masochism theory. Therefore, narcissism would remain present in Freud's works through its reverberations in the approach of other phenomena.
\end{abstract}

keywords: Narcissism. Drive. Masochism.

\footnotetext{
${ }^{1}$ Doutorando em Psicologia Clínica pela Universidade de São Paulo. E-mail: eloysancarlo@yahoo.com.br

${ }^{2}$ Professora Titular no IPUSP. Membro efetivo da SBSP da Universidade de São Paulo - Psicologia Clínica. E-mail: evamigliavacca@gmail.com
} 


\section{Introdução}

As reflexões sobre o narcisismo estiveram presentes por muito tempo na história da humanidade e recuperam alguns dos problemas existentes no mito grego. Segundo a narrativa mitológica, Narciso era um jovem e belo homem, filho do deus Céfiso e da ninfa Liríope, que acabou por se apaixonar intensa e mortiferamente por sua própria imagem refletida em um espelho de água. Esse tema retornou constantemente no terreno artístico e foi retratado por pintores como Caravaggio ${ }^{1}$, Nicolas Poussin ${ }^{2}$, Salvador Dalí $^{3}$, dentre outros. No âmbito da psicologia, a primeira referência ao mito de Narciso para definir uma condição subjetiva foi feita por Binet em 1887, no texto Le fétichisme dans l'amour (ROUDINESCO; PLON, 1998). Posteriormente Havelock Elis (1898) e Paul Näcke (1899) também utilizaram dessa comparação para falar sobre o interesse erótico sobre si mesmo (LAPLANCHE; PONTALIS, 1994). O que esse quadro deixa claro é que quando Freud aborda o narcisismo, já existia uma considerável história. Não obstante, é impossível desprezar a importância de suas contribuições para o tema, que foi desenvolvido até um alto nível de complexidade conceitual, com várias implicações clínicas.

O narcisismo emerge como uma das grandes figuras da metapsicologia freudiana, que teve uma importância fundamental não apenas por permitir uma apreensão mais rigorosa de certas manifestações psíquicas, mas também por contribuir para algumas mudanças centrais da psicanálise. É este o caso da passagem do primeiro dualismo pulsional, fundado no embate entre pulsões do $\mathrm{eu}^{4}$ e pulsões sexuais, para o segundo dualismo, que contava com as pulsões de vida e de morte, ou ainda, a passagem da primeira para a segunda tópica.

"Narciso" (1594-1596)

"Eco e Narciso" (1627- 1628)

"Metamorfose de Narciso" (1937)

Este artigo faz a opção de utilizar a nomenclatura Eu e Supereu quando estiver falando sobreas instâncias psíquicas, porém preservando a nomenclatura ego e superego nas citações literais.
Apesar da importância desse conceito, é necessário reconhecer a grande dificuldade em se definir de maneira completa e rigorosa o seu significado na obra freudiana. Desde o seu surgimento, em 1910, até nas últimas obras do autor em 1938, o narcisismo passou por um processo de desenvolvimento, que modificou e ampliou o seu sentido. Assim, como aponta Miguelez (2007), conseguir uma definição única para o narcisismo é algo problemático, já que sob esse conceito Freud descreveu fenômenos tão diversos que seria lícito pensarmos esse fator como algo

[...] que tem muitas faces, múltiplos semblantes. Uma dela está voltada para a psicose, e todo um campo de trabalho de pesquisa surge se perguntar até que ponto o narcisismo ajuda hoje na compreensão desses ainda enigmáticos fenômenos. Outra face está voltada para a cultura e os fenômenos sociais. Outra, ainda, para as diferenças sexuais. E ainda haveria, em vários campos, outros semblantes (MIGUELEZ, 2007, p. 15-16).

Não é sem razão, portanto, que esse autor propõe a pluralização do termo, de maneira que estaríamos diante de narcisismos, ou seja, de um fenômeno dotado de multiplicidade, que recusa uma definição unívoca.

Porém, apesar dessas dificuldades, não é possível ignorar a necessidade de estudo desse conceito, dada a sua posição no conjunto metapsicológico. Para tentar abordar de maneira adequada esse fator, uma alternativa seria a apresentação do seu desenvolvimento histórico, salientando os pontos de maior relevância.

\section{O Desenvolvimento do Conceito Freudiano de Narcisismo}

Acompanhando a obra freudiana, nota-se que a primeira aparição do termo narcisismo se deu pela reedição em 1910 dos Três ensaios sobre a 
teoria da sexualidade, originalmente publicada em 1905. Nesse texto ao discutir sobre a perversão, Freud aborda a homossexualidade, tentando descobrir quais seriam as determinações psíquicas que estariam implicadas nas escolhas objetais feitas por indivíduos homossexuais. Ao pensar sobre a psicogênese dessa condição, Freud propõe que

[...] a psicanálise não trouxe até agora um esclarecimento completo da origem da inversão; não obstante, desvendou o mecanismo psíquico de sua formação e enriqueceu substancialmente a colocação dos problemas envolvidos. Em todos os casos investigados, constamos que os futuros invertidos atravessaram, nos primeiros anos de sua infância, uma fase muito intensa, embora muito breve de fixação na mulher (em geral, a mãe), após cuja superação identificaram-se com a mulher e tomaram a si mesmos como objeto sexual, ou seja, a partir do narcisismo buscaram homens jovens e parecidos com sua própria pessoa, a quem eles devem amar tal como a mãe os amou. (FREUD, 1996k, p.137).

Percebe-se, no trecho acima, que o narcisismo é utilizado para descrever um circuito de escolhas objetais, no qual o sujeito irá eleger um parceiro semelhante a ele mesmo, uma vez que está identificado com a figura materna. Essa breve menção ao narcisismo é, todavia, ainda lacunar. Não existe uma explicação clara para o que consiste realmente o narcisismo. A palavra é utilizada eminentemente como metáfora.

Ainda em 1910, Freud irá utilizar novamente o termo em outro escrito: Leonardo da Vinci: uma lembrança de infância (1910), que é um texto fundamental por ser o primeiro trabalho de Freud em que o narcisismo está presente na redação original. Essa obra visa à exposição de algumas das características psíquicas do artista renascentista, que é apresentado como uma "pessoa emocionalmente homossexual" (FREUD, 1996e, p.104). Novamente, o narcisismo aparece para tentar explicar os meandros da escolha dos objetos feita pelos homossexuais. Segundo Freud, tais pessoas executariam

[...] um retorno ao auto-erotismo, pois os meninos que ele agora ama à medida que cresce, são, apenas, figuras substitutivas e lembranças de si próprio durante sua infância - meninos que ele ama da maneira que sua mãe $o$ amava quando ele era criança. Encontram seus objetos de amor segundo o modelo do narcisismo, pois Narciso, segundo a lenda grega, era um jovem que preferia sua própria imagem a qualquer outra, e foi assim transformado na bela flor do mesmo nome (FREUD, 1996e, p. 106).

Desses dois textos iniciais, é possível destacarmos algumas categorias importantes para a historiografia do narcisismo. Inicialmente, cabe ressaltar que o narcisismo é utilizado mais como uma metáfora do que como um conceito propriamente dito, uma vez que o termo é utilizado para fazer uma comparação com o mito grego. Não existe uma definição dos aspectos dinâmicos, econômicos ou tópicos. Também é possível notar uma vinculação entre o narcisismo e a homossexualidade, que nesse momento da teoria era considerada como um exemplo de perversão. Além disso, não há qualquer diferenciação entre o narcisismo e o auto-erotismo, que são apresentados como quase coincidentes.

Esse panorama começa a ser alterado com o texto "Notas psicanaliticas sobre um relato autobiográfico de um caso de paranoia (Dementia Paranoides)" (1911) (FREUD, 1996g), também conhecido como Caso Schreber. Como salienta Green (1989) é nesse momento que o narcisismo adquire o status conceitual, deixando de ser apenas uma figura metafórica. Desde os Três ensaios sobre a teoria da sexualidade (1905), Freud (1996k) diferenciava dois modos de organização libidinal: inicialmente o auto-erotismo, pautado pela parcialidade das pulsões, que encontram satisfação no próprio corpo fragmentado do bebê e posteriormente as relações objetais, marcadas pela possibilidade de investir libidinalmente objetos diferentes do sujeito. O que o Caso Schreber vai apresentar como novo é que entre esses dois momentos constitutivos do desenvolvimento libidinal existiria uma fase intermediária, ou seja, seria possível notar

[...] um estádio do desenvolvimento da libido, entre o auto-erotismo e o amor objetal. Este estádio recebeu o nome de narcisismo. O que acontece é o seguinte: 
chega uma ocasião, no desenvolvimento do indivíduo, em que ele reúne seus instintos sexuais (que até aqui haviam estado empenhados em atividades autoeróticas), a fim de conseguir um objeto amoroso, e começa a tomar a si próprio, seu próprio corpo, como objeto amoroso, sendo apenas subseqüentemente que passa daí para a escolha de alguma outra pessoa que não ele mesmo como objeto. Essa fase equidistante entre o auto-erotismo e o amor objetal pode, talvez, ser indispensável (FREUD, 1996g, p. 68).

É importante notar que essa nova compreensão sobre o narcisismo partiu em um primeiro momento da análise do fenômeno paranoico, mas subsequentemente acabou por ser considerado como uma etapa universal do desenvolvimento da libido, incidindo em todas as três estruturas de personalidade.

Além de permitir melhor compreensão sobre os aspectos psicogenéticos, o Caso Schreber também apresenta o narcisismo inserido em uma dimensão psicodinâmica. Segundo Freud, a paranoia seria uma manifestação psicótica ligada a esse estado, uma vez que "os paranoicos trouxeram consigo uma fixação no estádio do narcisismo" (FREUD, 1996g, p. 79).

Assim, diferentemente dos textos anteriores, o narcisismo começa a ser inserido em uma compreensão psicogenética, pois é um dos estádios da libido, uma concepção econômica, afinal uma regressão maior ou menor ao narcisismo imprimiria características diferenciadas da paranoia e uma dimensão psicodinâmica, já que comparece como um dos dados do conflito psíquico. É visível o progressivo avanço da visão freudiana sobre esse tema, que embora seja em larga medida mantido nos escritos posteriores, ainda irá receber importantes acréscimos.

Um desses momentos consiste nas reflexões tecidas no texto Totem e tabu (1913) (FREUD, 1996j), que conforme o próprio Freud afirmava, era um de seus trabalhos mais caros. Um dos aspectos da sua reflexão antropológica consistia no processo de desenvolvimento da civilização que, ao longo da história contaria com diversas maneiras de estruturação de pensamento, de maneira que seria possível indicar algumas fases que se sucederiam. O percurso proposto pelo autor conta com o período animista, religioso e científico.

Especificamente em relação ao animismo, é possível observarmos que esse modo de pensamento seria a "doutrina dos espíritos", ou seja, acreditar que todos os elementos da realidade externa, sejam pessoas ou objetos inanimados, possuiriam alma. A tal quadro se soma a crença de ser possível interferir nessa mesma realidade por meio de um expediente especial denominado magia. O pensamento mágico atuaria desprezando as conexões causais efetivas entre os vários elementos do mundo e se pautando a partir do desejo do sujeito; isso significa dizer "o homem primitivo tinha uma crença imensa no poder de seus desejos" (FREUD, 1996j, p. 94).

Essa maneira de manifestação do pensamento se relacionaria com certos regimes de organização libidinal, pois o "homem primitivo atribui uma alta valorização - ao nossos olhos uma supervalorização - aos atos psíquicos. Essa atitude pode ser perfeitamente relacionada com o narcisismo e ser encarada como um componente essencial deste" (FREUD, 1996j, p. 100).

Nesse momento da elaboração conceitual, o narcisismo é encarado como uma fase posterior ao auto-erotismo, na qual o sujeito começa a investir objetos. Porém, esse objeto "não é um objeto externo, estranho ao sujeito, mas se trata de seu próprio ego, que se constitui aproximadamente na mesma época" (FREUD, 1996j, p. 99). Aqui já notamos o início de uma discussão sobre a psicogêneses do eu, fator esse que será melhor desenvolvido em "Sobre o narcisismo: uma introdução" (1914) e que irá ressoar em $O$ ego e o id (1923) (FREUD, 1996h, 1996i).

Somente após esse período narcisista é que seria possível outras relações objetais, entretanto, vale notar, que o narcisismo não desaparece por completo em etapas ulteriores da vida, o que significa que: 
[...] o ser humano permanece até certo ponto narcisista, mesmo depois de ter encontrado objetos externos para sua libido. As catexias de objetos que efetua são, por assim dizer, emanações de sua libido que ainda permanece no ego e pode ser novamente arrastada para ele. A condição de apaixonado, que é psicologicamente tão notável e é o protótipo normal das psicoses, mostra essas emanações em seu máximo, comparadas com o nível de amor a si mesmo (FREUD, 1996j, p. 99).

É curioso notar nesse texto freudiano que várias teses que seriam consagradas no texto canônico do narcisismo em 1914 já estavam desenvolvidas. Podemos notar que a teorização sobre as formas de apresentação da libido já estava estabelecida, assim como a ideia da existência de dois momentos do narcisismo.

Portanto, não é sem razão que em Sobre o narcisismo: uma introdução (1914), Freud (1996i) aponta que as investigações sobre os fenômenos narcísicos decorrem de três fontes principais: o estudo da homossexualidade, da psicose e da mente dos povos primitivos. É esse o texto central para a discussão sobre a problemática narcísica, pois, por um lado, ele é a síntese do que foi anteriormente discutido na obra do autor, mas por outro, também é o ponto de partida de posteriores elaborações.

Além disso, também deve ser sublinhado que um dos motivos que contribuíram para a publicação dessa obra de 1914 está ligada a fatores políticos da instituição psicanalítica. Sobre o narcisismo não é apenas uma apresentação altamente elaborada sobre um fenômeno metapsicológico, mas também uma contraposição a ideias de autores que ameaçavam alguns dos pilares da teoria freudiana, em especial a questão do protesto masculino elaborada por Adler, bem como a compreensão da psicogêneses da psicose e a existência de uma "libido dessexualizada" proposta por Jung (COSTA, 2003; GAY, 2010).

O fato é que tanto pela carga teórica, quanto pelo conteúdo político, Sobre o narcisismo é um texto supercondensado, com várias teses complexas apresentadas simultaneamente, essa condição fez com que Freud não ficasse satisfeito com o resultado final e levou Laplanche (1985, p. 72) a afirmar que esse escrito "foi concebido apressadamente, febrilmente e sem dúvida com entusiasmo, foi rapidamente considerado imperfeito, senão monstruoso". Diante disso é necessário sublinhar que o presente artigo busca somente apresentar algumas das principais teses contidas no texto de 1914.

Um dos fatores centrais é justamente a teorização sobre as formas libidinais. Assim, inicialmente existiria o auto-erotismo e em seguida, o que se notaria seria o estabelecimento do narcisismo primário, que consiste em uma organização posterior, na qual as pulsões seriam unificadas e passariam a investir um objeto, que contudo, não pertenceria ao mundo externo, mas seria o próprio sujeito. Ao pensar na diferenciação entre esses dois estados Freud propõe que

$$
\begin{aligned}
& \text { Estamos destinados a supor que uma unidade } \\
& \text { comparável ao ego não pode existir no indivíduo } \\
& \text { desde o começo; o ego tem que ser desenvolvido. } \\
& \text { Os instintos auto-eróticos, contudo, ali se encontram } \\
& \text { desde o início, sendo, portanto, necessário que algo } \\
& \text { seja adicionado ao auto-erotismo - uma nova ação } \\
& \text { psíquica- a fim de provocar o narcisismo (FREUD, } \\
& \text { 1996i, p. 84). }
\end{aligned}
$$

É esse quadro, que conta com uma unificação pulsional, que se nomeia de narcisismo primário, momento no qual se notaria uma "catexia libidinal original do ego" (FREUD, 1996i, p. 83). Tal concentração libidinal, esse "represamento", acaba por ter impactos na esfera econômica, uma vez que provoca um aumento tensional. Segundo a teoria freudiana, isso acarretaria o estabelecimento de uma situação desprazerosa, o que convoca o sujeito a procurar maneiras de promover o rebaixamento tensional, para atender as exigências do princípio do prazer.

Um dos mecanismos utilizados é o investimento da libido em objetos externos. As relações objetais surgem então devido a uma impossibilidade de manutenção indefinida do narcisismo primário. Assim, essa necessidade de investimentos objetais 
emerge "quando a catexia do ego com a libido excede certa quantidade. Um egoísmo forte constitui uma proteção contra o adoecer, mas, num último recurso, devemos começar a amar a fim de não adoecermos, e estamos destinados a cair doentes se, em consequência da frustração, formos incapazes de amar" (FREUD, 1996i, p. 62).

A libido que anteriormente investia o eu, passa então a investir os objetos. Contudo, tal configuração nem sempre se mantém de maneira indefinida. Sob determinadas circunstâncias é possível que essa relação objetal chegue a um fim, porém nessas circunstâncias a libido empregada não é simplesmente destruída, mas retorna para o seu local de origem.

Esse refluxo libidinal, que tem como destino novamente o eu, faz emergir o narcisismo secundário. Tal condição é facilmente observada clinicamente, por exemplo, nos estados de luto. Esse retorno para o narcisismo é uma etapa necessária para que, aos poucos, outras relações objetais possam surgir. Existe, portanto, uma antítese entre a libido objetal e egóica: quanto mais uma é empregada, menos se nota a outra.

Certamente as relações objetais são um dos destinos do narcisismo primário, todavia esse não é o único desdobramento. Simultaneamente também se nota que uma parte é empregada na formação das instâncias ideais. O que se pode perceber é que existe certa relutância em abandonar a crença em uma perfeição infantil e quando as vivências de uma pessoa acabam por apontar para a falta e a castração, o sujeito começa a construir um eu ideal. Tal elemento é compreendido como sendo tão perfeito quanto a própria pessoa julgou anteriormente que ela própria fosse.

O estabelecimento desse eu ideal funcionará como um modelo a ser seguido, contribuindo para o estabelecimento de uma diferenciação no interior do próprio eu, que além de ser um modelo, também atuará como um avaliador dos feitos do sujeito. Essa nova faceta no interior do eu é nomeada como ideal do eu e é de suma importância uma vez que "para o ego, a formação de um ideal seria o fator condicionante da repressão" (FREUD, 1996i, p. 100).

Tanto o eu ideal, quanto o ideal do eu, são elementos que do ponto de vista tópico se localizam ao lado do inconsciente. Essa característica irá abalar fortemente a compreensão freudiana da organização do psiquismo, basta lembrar que desde $A$ interpretação dos sonhos (1900) (FREUD, 1996d) e durante toda a vigência da primeira tópica, o conflito psíquico era explicado por uma oposição. De um lado teríamos o inconsciente, os processos primários, os conteúdos recalcados, as pulsões sexuais e o princípio do prazer, de outro contaríamos com o Eu, que abarcaria o pré-consciente e a consciência, processos secundários, pulsão de autoconservação e o princípio de realidade. O que o narcisismo introduz é que o próprio eu possui uma parcela fundamental que é inconsciente. Costa (2003) analisando esse quadro propõe que:

Com o narcisismo, o Ego passa de aliado à Quinta coluna de homoestase mental. Freud tenta reestruturar a teoria. Propõe em sua Segunda tópica a divisão do Ego numa parte inconsciente e numa parte preconsciente-consciente. Esta saída trouxe para a psicanálise mais desconforto que alívio, pois uma pergunta ficava no ar: que Ego é este que ao mesmo tempo que se define com aquilo que recalca possui as mesmas propriedades do recalcado? Onde e como ficava a distinção tópica, econômica e dinâmica que fazia do conflito psíquico uma noção teoricamente coerente? O ego deixava de ser o puro embaixador da realidade junto ao psiquismo. Em sua origem narcísica não era mais o outro na realização alucinatória do desejo. Não apenas o narcisismo, a teoria das identificações desde luto e melancolia passando pela Psicologia das Massas ... até o Ego e o Id também apontava para esta gênese insuspeita da estrutura egóica. Objetivos do Ego e finalidades da libido de repente confundiam-se, fundiam-se, minando nesta fusão os alicerces da metapsicologia. O Ego tornavase agora uma representação do tipo de representação sexual recalcada da primeira tópica (COSTA, 2003, p. 20-21).

Isso significa que o narcisismo é um dos responsáveis, embora não seja o único, pela passagem da primeira para a segunda tópica. $\mathrm{O}$ seu 
papel nessa mudança pode ser resumido a partir de três pontos: em primeiro lugar o narcisismo alterou a compreensão sobre o que é o eu e o seu processo de formação; em segundo lugar, justamente por discutir as instâncias ideais, ele embasou o que posteriormente seria conhecido por supereu; por fim, e este é o ponto mais importante, o narcisismo alterou a noção de conflito psíquico, exigindo uma remodelação teórica.

O papel do narcisismo para a chamada "virada dos anos 20" não se limitou às suas contribuições para a segunda tópica. Tão importante quanto essa mudança, foi a modificação da teoria pulsional. O conceito de pulsão aparece muito cedo na obra freudiana, já sendo bem desenvolvida em obras como Os três ensaios da teoria da sexualidade (1905) (FREUD, 1996k). Contudo, é somente em 1910 que será apresentado um modelo que articule simultaneamente a dimensão pulsional e o conflito psíquico.

$\mathrm{Na}$ obra $A$ concepção psicanalítica $d a$ perturbação psicogênica da visão (1910), Freud (1996a) propõe que existiria um embate entre duas manifestações bem diferentes da pulsão. Por um lado existiriam as pulsões do eu, que se ocupariam da manutenção da vida e que possuiriam um tipo de energia claramente definido: o interesse. Por outro lado, em oposição ao primeiro tipo, existiria a pulsão sexual, que contaria como tipo de energia a libido.

O desenvolvimento da teoria do narcisismo impõe, todavia, algumas questões que desafiam essa forma de organização pulsional bem delimitada. Ao postular a existência do narcisismo primário, Freud sinaliza que o eu é constituído pela libido e que se serve desse tipo de energia para se relacionar com o mundo. Dessa maneira uma separação entre um campo próprio ao eu, e outro diferente, ligada à esfera sexual, perde gradualmente sua clareza.

Na verdade, esses incômodos só serão resolvidos a partir de 1920 com a proposição da segunda teoria pulsional. A pulsão de vida abarcará o que anteriormente era denominado de pulsões do eu e sexuais, eliminando assim a dicotomia entre esses elementos, uma vez que passam a ser concebidos como expressões diferentes do mesmo fenômeno. Em contraposição à pulsão de vida, Freud irá propor a existência da pulsão de morte, que é a manifestação da tendência existente em todo ser vivo de retornar ao estado mais simples, menos diferenciado, ou seja, a inorganicidade.

O que essa trajetória permite que se compreenda é que o narcisismo possui uma história complexa, que lhe conferiu um lugar de destaque na teoria freudiana. Isso se deve não apenas a sua capacidade heurística de desvelar vários fenômenos e permitir todo um novo campo de ação clínica. Afinal, para além desses dados, o narcisismo também comparece como um fator importante para mudanças relevantes da teoria freudiana, seja a passagem da primeira para a segunda tópica ou da primeira para a segunda teoria pulsional.

Todavia, embora possamos acompanhar um período de franco desenvolvimento entre 1910 e 1923 o que assistimos após isso é um progressivo desaparecimento das discussões sobre esse conceito. A sua frequência diminui significativamente, assim como também não notamos grandes acréscimos. Vários autores sublinham essa problemática, como, por exemplo, Laplanche (1985), Miguelez (2007), Costa (2003), embora nenhum deles ofereça uma resposta sobre os motivos responsáveis por tal quadro. Green (1989, p. 30) analisando essa questão aponta que,

"Sabe-se que o narcisismo, abandonado por Freud por razões pretensamente teóricas, fica em suspenso depois de "Além do princípio do prazer". O "Compêndio" mal o menciona. Assim vão os conceitos. Como amores efêmeros, são abandonados quando outros mais atraentes nos chamam".

Acreditar que o narcisismo foi simplesmente abandonado, como uma paixão passageira, talvez não seja uma alternativa dotada de rigor 
metodológico. É possível que ele tenha continuado presente na reflexão freudiana, por meio das suas ressonâncias. Aparentemente é esse o caso da teorização sobre o masoquismo, que aponta que as elaborações sobre o narcisismo ajudaram a iluminar certos processos que estariam ligados à pulsão de morte. Porém para uma avaliação mais detida dessa hipótese é útil uma apresentação sintética da teoria freudiana sobre o masoquismo desenvolvida após a década de 1920.

\section{4: Novas Teorizações Sobre a Problemática Masoquista}

O masoquismo é um elemento que constantemente esteve presente na obra de Freud. Trata-se de um conceito essencial para a reflexão de diversos casos clínicos, tais como O homem dos ratos ou o homem dos lobos, assim como um fator importante nas construções mais estritamente metapsicológicas, presentificando-se, por exemplo, nas considerações sobre as relações que o eu trava com o supereu. Em alguns momentos é possível notar que o masoquismo foi tomado inclusive como objeto central de determinados escritos, como é o caso do artigo Bate-se em uma criança: uma contribuição para o estudo das perversões sexuais (1919). Tal quadro atesta a importância desse elemento para a psicanálise, que em 1924, no texto O problema econômico do masoquismo (FREUD, 2007), ganha novas formulações.

A retomada da discussão sobre o masoquismo nesse ponto específico da obra freudiana não é aleatória, mas sim fruto dos avanços conquistados a partir de 1920. O masoquismo é abordado nesse texto a partir de três manifestações distintas: como condição da excitação sexual, manifestação da dimensão do feminino e como a base de uma norma de conduta, o que permite que se sublinhe respectivamente o masoquismo erógeno, feminino e moral (FREUD, 2007).

Na verdade esses três registros estão intimamente relacionados e, em alguma medida, já tinham sido parcialmente analisados em outros momentos da obra do autor. A forma mais visível do masoquismo seria o feminino, uma vez que pode ser estudado a partir de manifestações da fantasia perversa, que normalmente possuem um roteiro bem semelhante, na qual o sujeito é "amordaçado, amarrado, golpeado, fustigado, maltratado de uma forma qualquer, obrigado a uma obediência incondicional ou humilhado" (FREUD, 2007, p. 2753). O que o conteúdo dessa cena perversa revela é que o sujeito deseja ser tratado como uma criança pequena, indefesa, dependente e que é essencialmente má. Essas elaborações já tinham sido tecidas pelo o autor anteriormente no texto Bate-se em uma criança, porém o que é apresentado como novo no texto de 1924 é que o aprofundamento da análise do conteúdo da fantasia aponta que, no limite, o que é verdadeiramente desejado é "ser castrado, suportar o coito ou parir" (FREUD, 2007, p. 2754), ou seja, situações tipicamente femininas.

Embora omasoquismo femininosejaclinicamente mais recorrente e fácil de ser observado, cabe notar que ele "repousa por completo no masoquismo primário erógeno, o prazer na dor" (FREUD, 2007, p. 2754). Esse ponto é de suma importância por indicar os momentos mais primitivos da constituição da subjetividade, na qual o sujeito se firma pelos modos como conduz as exigências pulsionais. O que Freud apresenta é que as forças eróticas possuem um grande desafio inicial, a saber, contornar a tendência imposta pela pulsão de morte ou de destruição de conduzir a substância viva ao estado inorgânico primitivo. Tal feito é realizado direcionando as exigências pulsionais para o mundo exterior, promovendo inclusive certa submissão das demandas mortíferas aos imperativos sexuais, sendo essa justamente a gêneses do sadismo.

Tal processo permite que se vislumbre a grande dificuldade de isolar cada uma dessas manifestações pulsionais; afinal, para que a vida se torne possível é necessário uma boa dose de dominação dos objetos do mundo externo. Em outras palavras, a destrutividade é, em certa medida, fundamental 
para a vida e isso se manifesta através daquilo que Freud nomeou como "pulsão de destruição, pulsão de apreensão ou vontade de poder" (FREUD, 2007, p. 2755). Todavia, nem toda a pulsão de morte segue esse destino, pois uma grande parte dela continua fixada no organismo, o que permite que se suponha a existência de um masoquismo primário erógeno, "que tem por objeto o próprio indivíduo" (FREUD, 2007, p. 2755).

O sadismo notado nas crianças seria então uma modificação do masoquismo, na qual a pulsão toma por objeto um elemento diferente do sujeito, porém esse caminho pulsional não é fixo, o que significa dizer que

[...] em determinadas circunstâncias o sadismo, o instinto de destruição orientado até o exterior ou projetado pode ser desviado até o interior, ou seja introjetado novamente, retornando assim, por regressão, a sua situação anterior. Nesse caso se produziria o masoquismo secundário que se adicionaria ao primitivo (FREUD, 2007, p. 2755).

Destarte, pode-se estabelecer linhas gerais dos primeiros movimentos da pulsão de morte em um sujeito: no início se nota o masoquismo primário, que perturbado pelas forças eróticas acaba por se converter, ao menos parcialmente, em sadismo, ou forças destrutivas dirigidas para o mundo, mas que pode retornar ao estado original e formar o masoquismo secundário.

Existe ainda uma terceira faceta do fenômeno: o masoquismo moral, que pode ser percebido clinicamente através dos sentimentos inconscientes de culpa ou da reação terapêutica negativa. $\mathrm{Na}$ verdade, essa manifestação masoquista surge como um grande entrave para o processo de análise, uma vez que se liga fortemente aos malefícios que as manifestações psicopatológicas estabelecem, preservando a condição da doença, tanto mais quanto ela provoca sofrimento.

O masoquismo moral é uma figura clínica difícil de ser descrita justamente por se confundir com a consciência moral que estrutura o sujeito. Com o estabelecimento da segunda tópica, Freud pode descrever que a moral está ligada intimamente ao supereu, que avalia e mede criticamente o eu a partir das formações ideais, valendo lembrar que tais formações são tributárias de um jogo envolvendo o narcisismo e a identificação com as figuras parentais. É o supereu que contém os imperativos que atuam sobre o sujeito e que, não raro, pode se mostrar duro, cruel, exigente e implacável com o eu.

Não é preciso ir muito longe para perceber que o supereu, como defensor da consciência moral presente em todos os neuróticos, trava relações com o eu coloridas pelo sadismo. A violência de suas demandas ea severidadedo seujulgamentoatestariam essa condição. Porém, de maneira simultânea e com resultados largamente semelhantes, também notamos que no interior do eu continuam a existir demandas de punição, que podem ser executadas tanto pela instância superegóica, quanto por outros fatores externos. É essa posição específica que Freud denomina de masoquismo moral. Assim, torna-se inteligível que "o sadismo do supereu e o masoquismo do eu se complementam mutuamente e se unem para provocar as mesmas consequências" (FREUD, 2007, p. 2758).

Evidentemente que esse masoquismo moral encontra suas raízes no próprio masoquismo erógeno, que estrutura as pessoas de uma maneira geral. Ele é, portanto, a persistência de organizações pulsionais infantis na vida adulta.

\section{Os Destinos do Narcisismo após 1920: O Masoquismo e os Contornos da Pulsão de Morte}

Investigar as transformações conceituais do narcisismo não é algo límpido e imediatamente disponível na obra freudiana. Por um lado notamos que do seu surgimento em 1910 até a chamada "virada dos anos 20", o narcisismo se constituiu como uma peça central para a metapsicologia e contribuiu tanto para a redefinição da teoria pulsional, quanto para o estabelecimento da segunda tópica. Foi inclusive um conceito dotado de relevância política, já que 
foi tomado como um dos pontos de apoio contra as concepções adlerianas e junguianas. Porém, por outro lado, notamos que após a publicação de $O$ ego e o id (1923), a frequência com que o termo narcisismo emerge na obra freudiana decai significativamente e, principalmente, acréscimos conceituais relevantes ou retificações são cada vez mais raros (GREEN, 1989; MIGUELEZ, 2007). Isso não significa, no entanto, que Freud tenha simplesmente abandonado o conceito, uma vez que ele continua presente mesmo nos últimos escritos do autor, como em Moisés e o monoteísmo (1938) e O Esboço de psicanálise (1938), (FREUD, 1996f, 1996c).

Esse quadro torna lícito o questionamento sobre o que ocorreu com o narcisismo após 1920. Um dos caminhos possíveis é que as reflexões tecidas sobre esse conceito continuaram vivas na obra freudiana por impactar outros pontos da obra do autor, ou seja, aquilo que Freud pensou sobre o narcisismo serviu como base para o desvelamento e organização de outros fenômenos psíquicos. Um exemplo desse processo é a redefinição do conceito de masoquismo com base na metapsicologia do narcisismo.

Como vimos anteriormente, as ideias sobre o narcisismo são plurais em Freud, pois dizem respeito a várias estruturas e abordam configurações psíquicas que são largamente diferentes entre si (MIGUELEZ, 2007). Apesar disso, ao tomarmos as formulações estabelecidas após 1914, no texto Sobre o narcisismo: uma introdução, que se mostraram contribuições mais perceptíveis para a chamada virada dos anos 20, podemos formar um quadro sintético. Assim, inicialmente existiria o auto-erotismo, que era marcado pela parcialidade das pulsões, que investiam parcelas de um corpo fragmentado; posteriormente, pela “introdução de uma nova ação psíquica” emergiria o narcisismo primário, que era caracterizado pelo investimento libidinal no próprio sujeito que contava com um sentido mais próximo de uma totalidade. Tal configuração abriria espaço, por um lado, para as formações ideais, mas por outro também permitiria o estabelecimento das relações objetais, que consistem em um investimento libidinal em fatores diferentes do sujeito. Esse tipo específico de investimento, sob determinadas condições, poderia ser rompido, fazendo com que a libido refluísse novamente para o eu, configurando o narcisismo secundário.

Esse quadro diz respeito a um processo de desenvolvimento libidinal, ou seja, está ligado às forças eróticas da pulsão de vida. O que é interessante ser notado é que ele contém pontos de semelhança com as descrições freudianas sobre o desenrolar do masoquismo, que é um fenômeno ligado de maneira mais estreita aos aspectos mortíferos da pulsão. A existência do masoquismo primário, que incide primitivamente sobre o sujeito; seguido do desvio das forças da pulsão de morte para o mundo externo através do sadismo ou da pulsão de dominação e que em determinadas situações podem retornar para o sujeito, no chamado masoquismo secundário, parecem fortalecer tal semelhança. Soma-se a isso o fato de que também foi descrito por Freud a existência de um masoquismo moral, que intervém na relação que o eu estabelece com o supereu.

Se a hipótese apresentada aqui for procedente, seria possível a construção de um esquema mostrando os pontos de aproximação entre narcisismo e masoquismo: 


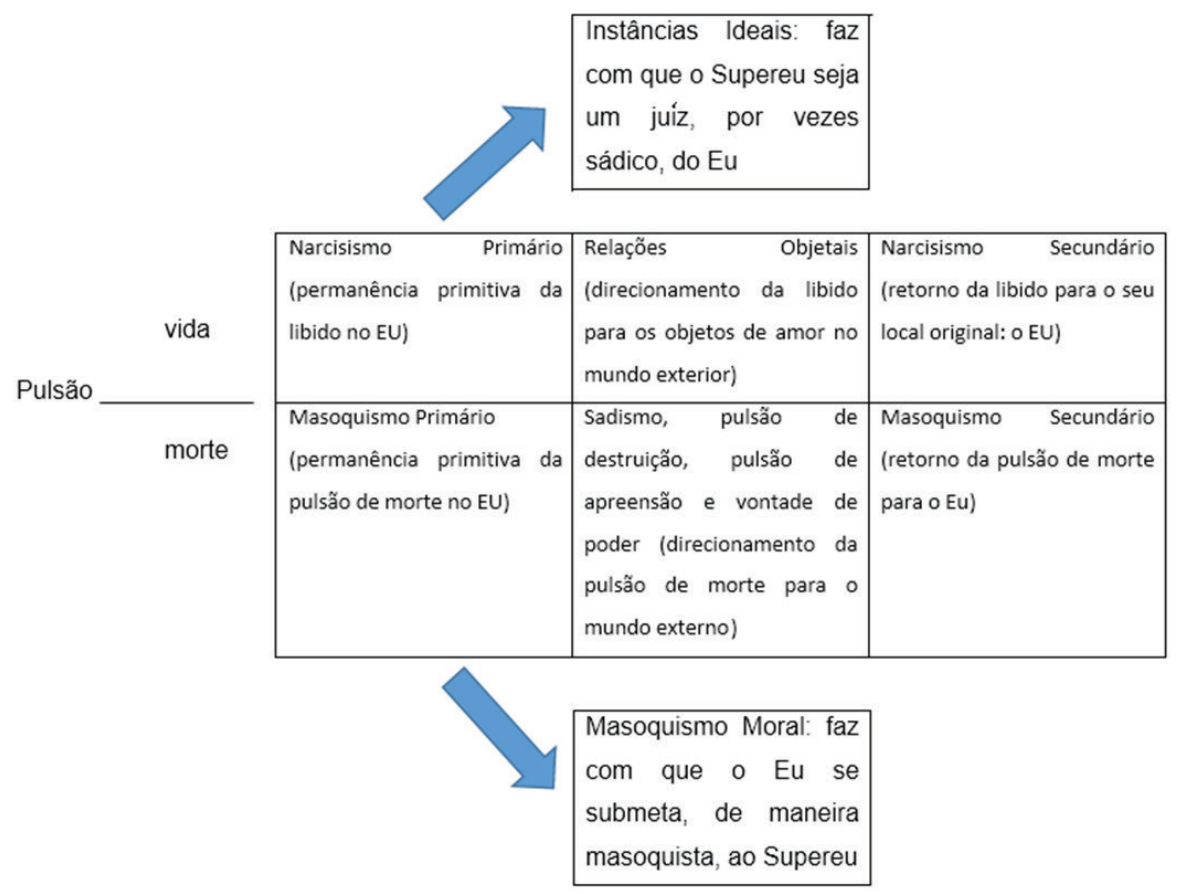

Evidentemente que não se deseja extrair desse panorama a tese de que o narcisismo tenha sofrido uma mera transformação em masoquismo, haja vista que, em última instância, eles efetivamente dizem respeito a fatores diferentes, com implicações metapsicológicas distintas e com incidências clínicas diversas. Porém, apesar da não coincidência, existem aproximações que merecem ser sublinhadas.

Ainda que a frequência do termo "narcisismo" tenha diminuído após 1920, o tipo de reflexão construída no seu processo de desenvolvimento, principalmente aquela notada de 1914 em diante, continuava presente na pena freudiana. Assim, esse conceito ressoa na compreensão freudiana de masoquismo, ao notarmos que em ambos casos existe uma força pulsional que primitivamente está localizada no sujeito, cuja uma parte é refletida para o mundo externo, mas que eventualmente pode retornar para a pessoa. Além disso, essa força pulsional irá regular a relação que o eu estabelece com o supereu.

\section{Considerações Finais}

O narcisismo é um conceito dotado de grande relevância na obra de Freud e até a década 1920 ocupou um lugar de destaque nos seus escritos. Justamente por essa condição são enigmáticas as razões que levaram Freud a utilizá-lo de maneira cada vez menos freqüente após a publicação de $O$ ego e o id, tal como sublinham diversos autores (COSTA, 1993; GREEN, 1989; LAPLANCHE, PONTALIS, 1994).

Mesmo tendo ciência de tal quadro, seria errôneo afirmar que o narcisismo simplesmente deixou de ser uma referência importante. A análise das aproximações entre narcisismo e as novas conceitualizações sobre o masoquismo tecidas após 1924, indicam que varias das construções elaboradas no terreno da pulsão de vida e dinâmica libidinal, influenciaram nas definições psicodinâmicas ligadas à pulsão de morte.

Essas conexões, embora não sejamimediatamente perceptíveis na obra freudiana, apenas corroboram a afirmação feita pelo próprio autor de que essas 
duas manifestações da pulsão geralmente estão unidas. Assim, justamente por essa fusão, torna-se compreensível que vários dos fenômenos próprios dos movimentos libidinais e da pulsão de vida, encontrem contrapartidas semelhantes na pulsão de morte. Isso significa dizer que embora não exista uma simples transformação de um conceito em outro, o narcisismo continua presente na obra de Freud, mesmo após a segunda tópica e a segunda teoria pulsional, por iluminar outros fenômenos.

\section{Referências}

COSTA, J. F. Narcisismo em tempos sombrios. Rio de Janeiro: Graal, 1993.

FREUD, S. A concepção psicanalítica da perturbação psicogênica da visão. Rio de Janeiro: Imago, 1996a. (Edição Standard Brasileira das Obras Completas de Sigmund Freud, v. 11).

- Além do princípio do prazer. Rio de Janeiro: Imago, 1996b. (Edição Standard Brasileira das Obras Completas de Sigmund Freud, v. 18).

. Esboço de psicanálise. Rio de Janeiro: Imago, 1996c. (Edição Standard Brasileira das Obras Completas de Sigmund Freud, v. 23).

. Interpretação dos sonhos. Rio de Janeiro: Imago, 1996d. (Edição Standard Brasileira das Obras Completas de Sigmund Freud, v. 6).

Leonardo da Vinci e uma lembrança de sua infância. Rio de Janeiro: Imago, 1996e. (Edição Standard Brasileira das Obras Completas de Sigmund Freud, v. 11).

. Moisés e o monoteísmo. Rio de Janeiro: Imago, 1996f. (Edição Standard Brasileira das Obras Completas de Sigmund Freud, v. 23).

- Notas psicanaliticas sobre um relato autobiográfico de um caso de paranóia (Dementia Paranoides). Rio de Janeiro: Imago, 1996g. (Edição Standard Brasileira das Obras Completas de Sigmund Freud, v. 12).
. O ego e o id. Rio de Janeiro: Imago, 1996h. (Edição Standard Brasileira das Obras Completas de Sigmund Freud, v. 19).

. O problema econômico do masoquismo.

Madrid: Biblioteca Nueva, 2007. (Obras Completas, 3).

. Sobre o narcisismo: uma introdução. Rio de Janeiro: Imago, 1996i. (Edição Standard Brasileira das Obras Completas de Sigmund Freud, v. 14).

Totem e tabu. Rio de Janeiro: Imago, 1996j. (Edição Standard Brasileira das Obras Completas de Sigmund Freud, v. 13).

. Três ensaios sobre a teoria da sexualidade.

Rio de Janeiro: Imago, 1996k. (Edição Standard Brasileira das Obras Completas de Sigmund Freud, v. 7.

GAY, P. Freud uma vida para o nosso tempo. São Paulo: Companhia das Letras, 2010.

GREEN, A. Narcisismo de vida, narcisismo de morte. São Paulo: Escuta, 1989.

LAPLANCHE, J. Vida e morte em psicanálise. Porto Alegre: Artes Médicas, 1985.

LAPLANCHE, J.; PONTALIS, J. B. Vocabulário de psicanálise. São Paulo: Martins Fontes, 1994.

MIGUELEZ, O. M. Narcisismos. São Paulo: Escuta, 2007.

ROUDINESCO, E.; PLON, M. Dicionário de psicanálise. Rio de Janeiro: J. Zahar, 1998. 